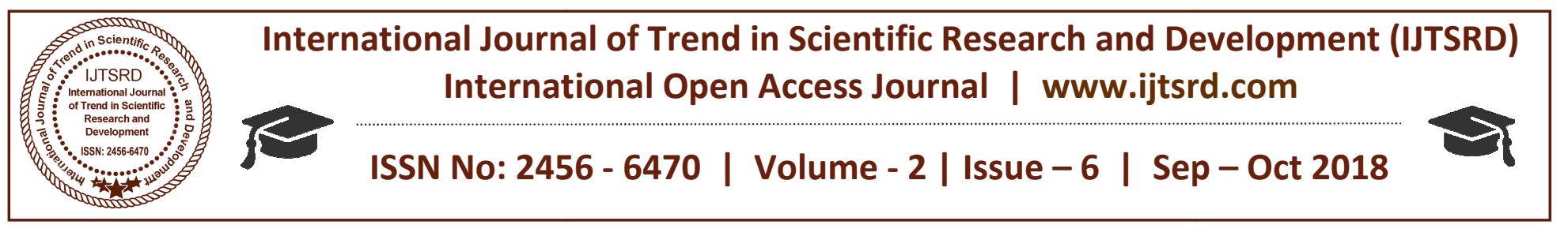

\title{
A Review on Transformer - Less UPFC
}

\author{
Shaikh Mohammed Tauseef ${ }^{1}$, S. M. Kulkarni ${ }^{2}$ \\ PG Scholar ${ }^{1}$, Associate Professor ${ }^{2}$ \\ Department of Electrical Engineering, PES College of Engineering, Aurangabad, Maharashtra, India
}

\section{ABSTRACT}

This paper is a review of an innovative technique with a new concept of transformer-less unified power flow controller (UPFC). The Transformer-less UPFC is based on two cascade multilevel inverters (CMIs), which reduce the complexity of the circuit. The construction of the conventional UPFC consists of two back-to-back inverters which results in complexity and bulkiness which involves the transformers which are complication for isolation \& attaining high power rating with required output waveforms. The proposed controller will reduce the cost and space as compared to the conventional UPFC. A multilevel configuration technique will be used to reduce the total harmonic content and thus increases the overall efficiency of the system.

\section{INTRODUCTION}

The control of an AC power system in real time is involved because power flow is a function of the transmission line impedance, the magnitude of the sending and receiving end voltages, and the phase angle between these voltages.

In recent years, demand for electric power has continued to grow hence to achieve greater operating flexibility and better utilization of existing power systems the concept of flexible AC transmission systems or FACTS is been introduced. The FACTS technology is a collection of Controllers, which can be applied individually or in coordination with others to control one or more of the interrelated system parameters. The most versatile FACTS device that can be used to achieve power flow control is the Unified power flow controllers (UPFCs).

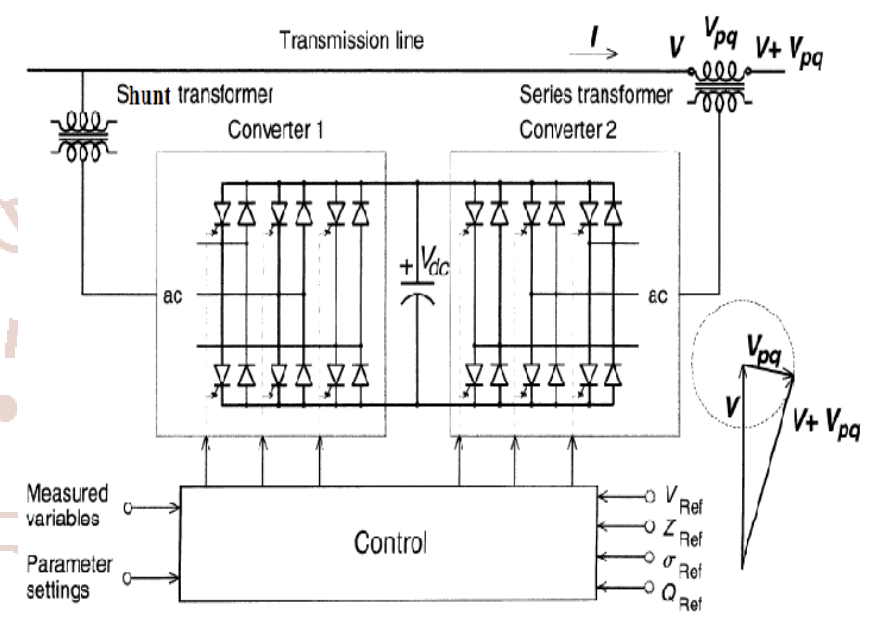

Fig. 1:- The Conventional UPFC

The Unified Power Flow Controller (UPFC) concept was proposed by Gyugyi in 1991. The UPFC was devised for the real-time control and dynamic compensation of ac transmission systems, providing multifunctional flexibility required to solve many of the problems facing the power delivery industry.

The UPFC is able to control, simultaneously or selectively, all the parameters affecting power flow in the transmission line (i.e., voltage, impedance, and phase angle), and this unique capability is signified by the adjective "unified" in its name. It can also independently control both the real and reactive power flow in the line. It proportionally increases the load capability of existing transmission lines.

There are several advantages of the conventional UPFC, but even though it suffers from the requirement of bulky zigzag transformers to interface the inverters to transmission lines, which makes the UPFC bulky and slow responding to dynamic load changes. To overcome such drawbacks of conventional UPFC, recently, a modular transformerless UPFC based on Cascaded Multi-level inverters (CMIs) has been proposed. 


\section{Theory of Transformer - Less UPFC}

The proposed transformer-less UPFC configuration is shown in Fig. 2(a), which consists of two CMIs: series CMI and shunt CMI.

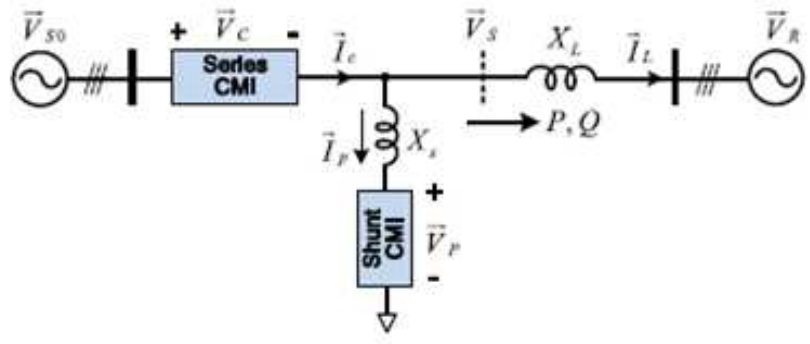

Fig. 2(a):-

The series CMI is directly connected in series with the transmission line and the shunt CMI is directly connected in parallel to the line but after the series CMI. Each CMI, as shown in Fig. 2(b) and (c), is composed of a number of cascade H-bridge or halfbridge modules.
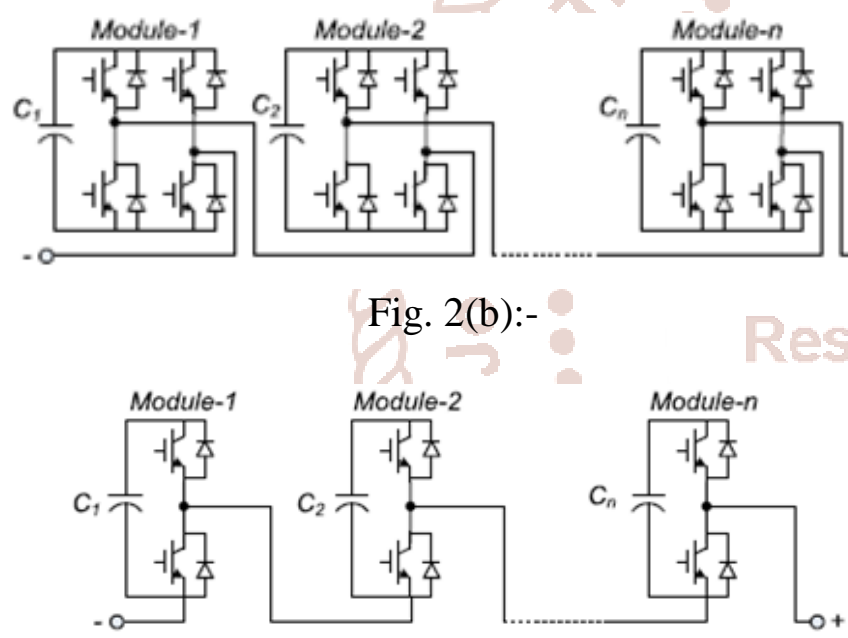

Fig. 2(c):-

Here are the unique features of the new configuration:

1. Unlike the conventional back-to-back dc link coupling, there is no transformer needed in the CMI-based UPFC; hence, the new UPFC can achieve low cost, light weight, small size, high efficiency, high reliability, and fast dynamic response;

2. The shunt inverter is connected after the series inverter, which is distinctively different from the traditional UPFC. Each CMI has its own dc capacitor to support dc voltage;

3. There is no active power exchange between the two CMIs and all dc capacitors are floating;

4. The new UPFC uses modular CMIs and their inherent redundancy provides greater flexibility to system design and higher reliability.

\section{Advantages}

$>$ Improves voltage profile for the duration of the transient conditions in the power transmission systems.

$>$ Low THD of output voltage.

$>$ Low switching loss.

$>$ High efficiency.

$>$ Independent active and reactive power flow control over the transmission line.

\section{Applications}

$>\mathrm{AC}$ transmission, distribution, utilization of electrical energy.

$>$ Power grid.

Transmitting electrical energy over long distances.

$>$ Electricity supply industry.

Used to couple stages of amplifiers and to match devices such as microphones and record players

\section{Conclusion}

In this paper, review of a new transformer-less UPFC based on a novel configuration of two CMIs was proposed. It has been discussed that the new UPFC can achieve the same controllability as the traditional UPFC. However, the traditional UPFC consisting of two back to-back inverters requires bulky isolation and zigzag transformers. The new UPFC consisting of two CMIs offers several advantages over the traditional UPFC, such as completely transformer-less and highly modular structure, light weight, high efficiency, high reliability, low cost, and fast dynamic response. The new transformer-less UPFC is, therefore, very well suited for fast and distributed power flow control of wind and solar power transmission.

\section{References}

1. N. G. Hingorani and L. Gyugyi, UnderStanding FACTS: concept and technology of flexible AC transmission systems. New York: IEEE Press, 2000.

2. L. Gyugyi, "Unified power-flow control concept for flexible AC transmission systems," IEE Proc. C Gener., Transmiss. Distrib., vol. 139,pp. 323331, 1992.

3. H. Akagi, S. Inoue, and T. Yoshii, "Control and performance ofa transformerless cascade PWM STATCOM with star configuration," IEEE Trans. Ind. Appl., vol. 43, no. 4, pp. 1041-1049,Jul./Aug. 2007. 